\title{
DWARF-COLONY VARIANTS OF STAPHYLOCOCCUS AUREUS RESISTANT TO AMINOGLUCOSIDE ANTI- BIOTICS AND TO A FATTY ACID
}

\author{
R. W. LACEY \\ Department of Clinical Pathology, Bristol Royal Infirmary
}

DURING an investigation of the action of lipids on bacteria, strains of Staphylococcus aureus were plated on nutrient agar containing an inhibitory concentration of linoleic acid. Incubation of the plates yielded some highly pigmented dwarf-colony variants that were more resistant than the wild strains to aminoglucoside antibiotics. Similar variants were obtained by plating the wild strains on a medium containing paromomycin, an aminoglucoside antibiotic. The variants isolated from both media had similar properties.

The purpose of this paper is to describe the properties of the variants and to consider whether their occurrence in vivo might be related to clinical problems with aminoglucoside therapy.

\section{MATERIALS AND METHODS}

Staphylococci. Forty-six strains of Staph. aureus had been recently isolated from lesions, or from the nose or skin of patients, and were maintained for up to $6 \mathrm{mth}$ on nutrient agar slopes at room temperature. They included members of phage-groups I, II and III. All were sensitive to the aminoglucoside antibiotics streptomycin, neomycin, paromomycin and gentamicin.

Media. Nutrient broth (Difco) and nutrient agar (Southern Group Laboratories) were used; the latter was a Hartley ox-heart digest agar containing $5 \mathrm{mg}$ para-aminobenzoic acid per $100 \mathrm{ml}$, but no added glucose. Linoleate medium was made by adding 0.20 per cent. $(\mathrm{w} / \mathrm{v})$ sodium linoleate to nutrient agar. Aminoglucoside media consisted of nutrient agar containing either paromomycin sulphate $(2.0 \mu \mathrm{g}$ per ml), neomycin sulphate $(2.0 \mu \mathrm{g}$ per ml) or streptomycin sulphate $(12.0 \mu \mathrm{g}$ per ml). Pigmentation was recorded after incubation of strains at $37^{\circ} \mathrm{C}$ for $72 \mathrm{hr}$ on nutrient agar, on 40 per cent. milk agar or on glycerol monoacetate medium (Willis and Turner, 1962). Lipase production was detected on Tween 80 medium (Gonzalez and Sierra, 1961). The $p \mathrm{H}$ of all the media was adjusted to 7.5.

Colony counts of viable bacteria were performed by the method of Miles and Misra (Miles, Misra and Irwin, 1938).

Antibiotic sensitivity tests were done by a diffusion method with " Mast" discs and also by determining the minimum inhibitory concentration (MIC) by a method in which doubling dilutions of antibiotic were incorporated into plates of nutrient agar. In the latter, each plate was inoculated by streaking a loopful of broth containing freshly suspended organisms from a plate culture. The MIC was taken as the least concentration that completely inhibited growth on all but the most densely inoculated areas. The Oxford staphylococcus (NCTC6571) was included as a control in each batch of tests.

The action of additional factors on growth. The variants were plated on nutrient agar, and the test substances were placed in antibiotic assay cups inserted in the surface of the seeded plate. Carbohydrates, fatty acids and nitrogenous compounds and their metabolic 
derivatives were obtained from B.D.H., Sigma Chemical Co. Ltd, or Koch-Light Laboratories Ltd. They were used as a 10 per cent. (w/v) aqueous solution unless incompletely soluble at this concentration, when a loopful of the pure substance was put directly on the seeded agar. Each agent was tested under aerobic and anaerobic conditions with incubation at $37^{\circ} \mathrm{C}$ for $20 \mathrm{hr}$. Testing for growth stimulants in broth was not reliable because of the instability of the variants; on plates the occasional large colony could be ignored.

Bacteriophage typing was done by the method of Blair and Williams (1961), with the addition of three new typing phages, 83A, 84 and 85 (Report, 1967). In order to stimulate some of the variants to grow sufficiently for phage typing, sodium pyruvate ( 0.6 per cent. $\mathrm{w} / \mathrm{v}$ ) was added to the medium.

\section{RESULTS}

\section{Isolation of small-colony variants on linoleate medium}

Drops of an overnight broth culture of each strain were deposited on the surface of 0.2 per cent. linoleate agar plates, and allowed to dry; the plates were incubated aerobically at $37^{\circ} \mathrm{C}$ for $72 \mathrm{hr}$. From 3 of the 46 strains tested, a few small, highly pigmented colonies appeared, representing less than 1 in $10^{6}$ of the inoculated bacteria. The rest of the strains did not yield small-colony variants; most of them were completely inhibited on this medium and the remainder grew profusely as normal colonies.

Subcultures were made from 13 dwarf colonies of strain no. 6736, and from 5 dwarf colonies from each of strains no. 6740 and 6745 . The properties of the wild strains and of the variants are summarised in table I. All of the dwarf-colony variants were resistant to streptomycin, neomycin, framycetin, paromomycin, kanamycin and gentamicin. The MIC of each antibiotic for the variant was at least 16 times the MIC of the corresponding wild strain.

On nutrient agar without linoleate, growth consisted mainly of dwarf colonies, but there were a few large-colony revertants. After 30 serial subcultures from the small colonies, the majority of the culture retained the dwarf-colony form.

When the variants were subcultured at $37^{\circ} \mathrm{C}$ in broth, they were outgrown by the reverting strains in $24 \mathrm{hr}$. But growth of the variants on nutrient agar containing neomycin at a level greater than the minimum bactericidal concentration for the wild strain prevented the appearance of large colonies. After several subcultures on this medium followed by plating out on antibioticfree agar, reverting colonies still appeared. Since the latter were fully sensitive to neomycin, they were evidently derived from the small-colony forms and had not survived from the original culture.

Several revertants were isolated that possessed normal sensitivity and growth, but retained the intense pigmentation of the variant. On further subculture, this pigmentation was lost. The variants therefore appeared to possess at least two distinct abnormalities, small-colony growth with resistance to aminoglucosides, and heightened pigmentation.

\section{Isolation of small-colony variants on paromomycin medium}

Dwarf-colony variants were obtained by inoculating the wild strains on a medium containing neomycin or streptomycin, but were most readily isolated 
in the presence of paromomycin. The optimum concentration of this antibiotic ( $2 \mu \mathrm{g}$ per $\mathrm{ml}$ ) was about 8 times the MIC for the wild strains. Overnight broth cultures of staphylococci were heavily inoculated on the paromomycin plates; a few highly pigmented small colonies appeared on each plate after 72 hours' incubation at $37^{\circ} \mathrm{C}$. In addition, there were some larger colonies that possessed variable pigment. Since each of the first 10 strains tested on paromomycin agar yielded small-colony forms, the remainder of the strains were not investigated.

Subcultures were made from 6 dwarf colonies on each paromomycin plate; all grew as small colonies on antibiotic-free media, and were resistant to each

TABLE I

Isolation of highly pigmented dwarf-colony variants on linoleate medium

\begin{tabular}{c|c|c|c|c|c}
\hline \multicolumn{2}{|c|}{ Wild strains } & Variants \\
\hline $\begin{array}{c}\text { Serial } \\
\text { no. }\end{array}$ & Source & $\begin{array}{c}\text { Phage-typing } \\
\text { pattern }\end{array}$ & $\begin{array}{c}\text { Proportion of } \\
\text { culture of } \\
\text { wild strain }\end{array}$ & $\begin{array}{c}\text { Number } \\
\text { examined } \\
\text { further }\end{array}$ & $\begin{array}{c}\text { Increase of } \\
\text { resistance to } \\
\text { aminoglucoside } \\
\text { antibiotics* }\end{array}$ \\
\hline 6736 & Normal skin & $6 / 47 / 54 / 75 / 83 \mathrm{~A} / 85$ & $4 \cdot 5 \times 10^{-8}$ & 13 & 16 to 128-fold \\
6740 & Boil & 80 & $2 \cdot 0 \times 10^{-7}$ & 5 & 16 to 128-fold \\
6745 & Nose & $81 / 80$ & $7 \cdot 7 \times 10^{-7}$ & 5 & 32 to 64-fold \\
\hline
\end{tabular}

* The sulphates of neomycin, streptomycin, framycetin, paromomycin, kanamycin and gentamicin.

of the aminoglucoside antibiotics. As an example, the proportional increase of resistance of the variants to gentamicin is shown in table II. Subculture of these variants to the linoleate medium gave small-colony growth after 72 hours' incubation at $37^{\circ} \mathrm{C}$, whilst most of the wild strains were inhibited by linoleate at this concentration.

\section{Properties of the small-colony variants from linoleate and paromomycin media}

All the variants grew as small, intensely pigmented colonies and were slidecoagulase positive. On the media used to study pigmentation, including glycerol monoacetate agar, each variant was more deeply coloured than the corresponding wild strain, but qualitative differences in pigmentation were not seen. The variants were resistant to all the aminoglucoside antibiotics tested, and thus differed from naturally occurring resistant strains of Staph. aureus in which neomycin or streptomycin resistance often occurs independently of gentamicin resistance (Barber and Waterworth, 1966; Chabbert, 1967).

Bacteriophage typing was carried out on 0.6 per cent. (w/v) pyruvate medium. When the dwarf-colony forms grew on this medium the phage-typing pattern was identical with that of the wild strain. Phage typing on medium containing fructose gave unsatisfactory results. 
All the variants produced frequent revertants to the normal colonial form, and the revertants were always sensitive to the aminoglucoside antibiotics.

TABLE II

Isolation of highly pigmented dwarf-colony variants on paromomycin medium

\begin{tabular}{|c|c|c|c|c|}
\hline \multicolumn{3}{|c|}{ Wild strains } & \multicolumn{2}{|c|}{ Variants } \\
\hline $\begin{array}{l}\text { Serial } \\
\text { no. }\end{array}$ & Source & Phage-group & $\begin{array}{l}\text { Proportion of culture } \\
\text { of wild strain }\end{array}$ & $\begin{array}{l}\text { Increase of resistance } \\
\text { to gentamicin* }\end{array}$ \\
\hline $\begin{array}{l}6730 \\
6731 \\
6732 \\
6733 \\
6734 \\
6735 \\
6736 \\
6737 \\
6738 \\
6739\end{array}$ & $\begin{array}{l}\text { Wound infection } \\
\text { Wound infection } \\
\text { Wound infection } \\
\text { Wound infection } \\
\text { Wound infection } \\
\text { Wound infection } \\
\text { Normal skin } \\
\text { Boil } \\
\text { Boil } \\
\text { Boil }\end{array}$ & $\begin{array}{r}\text { II } \\
\text { II } \\
\text { II } \\
\text { III } \\
\text { III } \\
\text { I } \\
\text { III } \\
\text { I } \\
\text { I } \\
\text { I }\end{array}$ & $\begin{array}{l}3.7 \times 10^{-7} \\
2 \cdot 2 \times 10^{-8} \\
1.0 \times 10^{-9} \\
4 \cdot 5 \times 10^{-6} \\
3.7 \times 10^{-7} \\
6 \cdot 8 \times 10^{-7} \\
3.4 \times 10^{-8} \\
4 \cdot 3 \times 10^{-6} \\
2.5 \times 10^{-7} \\
8.6 \times 10^{-7}\end{array}$ & $\begin{array}{r}16 \text {-fold } \\
32 \text {-fold } \\
16 \text {-fold } \\
64 \text {-fold } \\
128 \text {-fold } \\
16 \text {-fold } \\
32 \text {-fold } \\
32 \text {-fold } \\
32 \text {-fold } \\
64 \text {-fold }\end{array}$ \\
\hline
\end{tabular}

* Six variants of each culture examined.

TABLE III

Comparison of dwarf-colony variants isolated on linoleate and on paromomycin medium

\begin{tabular}{|c|c|c|}
\hline \multirow{2}{*}{ Information } & \multicolumn{2}{|c|}{ Variants from } \\
\hline & linoleate medium & paromomycin medium \\
\hline $\begin{array}{l}\text { Number examined } \\
\text { Microscopical appearance } \\
\text { Colony diameter, nutrient agar, } 37^{\circ} \mathrm{C}, 72 \mathrm{hr} \\
\text { Coagulase and catalase production } \\
\text { Pigmentation compared with wild strains } \\
\text { Increase of resistance to aminoglucoside anti- } \\
\text { biotics in comparison with wild strains } \\
\text { Reversion to normal growth associated with } \\
\text { return of sensitivity to these drugs }\end{array}$ & $\begin{array}{l}23 \\
\text { normal } \\
<2 \mathrm{~mm} \\
\text { positive } \\
\text { increased } \\
16 \text {-to } 128 \text {-fold } \\
\text { frequent }\end{array}$ & $\begin{array}{l}60 \\
\text { normal } \\
<2 \mathrm{~mm} \\
\text { positive } \\
\text { increased } \\
16 \text {-to } 128 \text {-fold } \\
\text { frequent }\end{array}$ \\
\hline $\begin{array}{l}\text { Growth stimulants } \\
\text { (a) fructose only } \\
\text { (b) fructose, pyruvate, acetate, oxaloacetate, } \\
\text { aspartate, and satellitism with certain } \\
\text { Gram-positive cocci } \\
\text { (c) no stimulant found . . . . }\end{array}$ & $\begin{array}{r}12 \text { (52 per cent.) } \\
8 \text { (34 per cent.) } \\
3 \text { (13 per cent.) }\end{array}$ & $\begin{array}{l}29 \text { ( } 48 \text { per cent.) } \\
3 \text { (5 per cent.) } \\
28 \text { ( } 47 \text { per cent.) }\end{array}$ \\
\hline
\end{tabular}

Many of the variants grew normally when fructose was added to the medium (table III); some variants were stimulated to normal growth by pyruvate, acetate, oxaloacetate or aspartate, in addition to fructose. It was also observed that all of the latter showed satellitism around colonies of certain staphylococci 
and micrococci. The growth of a few of the variants was not stimulated by any agent tested.

\section{Evidence for a defect in oxidative metabolism in the variants}

Further investigations were carried out on 2 of the variants from strain no. 6736 , one obtained from linoleate medium and one from paromomycin medium. The growth of both variants was stimulated by fructose under both aerobic and anaerobic conditions, and by acetate, pyruvate, oxaloacetate and aspartate only under aerobic conditions. When the enhanced growth was subcultured on to nutrient agar the small-colony form reappeared.

Agents that did not stimulate growth included glucose, galactose and ribose, and the intermediates of glycolysis and the tricarboxylic acid cycle other than those listed above. There was also no stimulation by any of the vitamins or cofactors, by purines or pyrimidines, by any amino acid other than aspartate, by saturated straight-chain fatty acids from acetate to stearate, by oleate or linoleate, or by the addition of $\mathrm{CO}_{2}$ (1-20 per cent.) to the atmosphere. The ability of the variants to grow on linoleate medium probably indicated resistance to that fatty acid.

The stimulation by acetate, pyruvate and oxaloacetate under only aerobic conditions might denote activity of the tricarboxylic acid cycle. Similarly, anaerobic and aerobic stimulation by fructose might indicate the operation of the glycolytic pathway under both these conditions, with fructose entering via fructose-6-phosphate. The failure of glucose to stimulate growth might therefore be due to its inability either to enter the cell or to be converted to fructose6-phosphate. It is noteworthy that the only amino acid to stimulate growth was aspartate, which when deaminated forms oxaloacetate. As the other amino acids also did not stimulate growth of the variants, these findings are more consistent with a defect in the uptake of the test substances than in their intracellular degradation.

Four of the variants that were stimulated by fructose, pyruvate and oxaloacetate were used in further investigations of satellitism in proximity to other organisms. Nutrient agar plates were inoculated uniformly with each of the variants and streaks of the test organisms were superimposed. Any growth stimulation was noted after 20 hours' incubation at $37^{\circ} \mathrm{C}$. Satellitism occurred only under aerobic conditions, and subculture from the stimulated growth gave the small colony form again. Variants from either linoleate or paromomycin agar were stimulated by the same organisms but not by others. All of 60 Staph. aureus, 65 per cent. of the other staphylococci and micrococci, 9 per cent. of beta-haemolytic streptococci, 4 per cent. of viridans streptococci and 4 per cent. of Streptococcus faecalis strains produced satellitism. A variety of other organisms, including fungi, did not enhance growth of the variants. Among the micrococci, the ability to cause satellitism showed a good correlation with the proposed classification of Baird-Parker (1965). Micrococci that did not oxidise glucose and were therefore assigned to subgroup 7 failed to produce satellitism, whereas nearly all of those that oxidised glucose (subgroups 1-6) also elicited satellitism (table IV). 
The mechanism of the satellitism proved difficult to define because of the lability of the stimulating factor. Broth filtrates, ultrasonically disrupted cells

TABLE IV

Satellitism* by certain dwarf-colony variants around micrococci

\begin{tabular}{|c|c|c|c|c|c|}
\hline \multirow{3}{*}{$\begin{array}{c}\text { Variant } \\
\text { of } \\
\text { strain } \\
\text { number }\end{array}$} & \multirow{3}{*}{$\begin{array}{l}\text { Isolated on medium } \\
\text { containing }\end{array}$} & \multicolumn{4}{|c|}{$\begin{array}{l}\text { Number of strains in which } \\
\text { satellitism around growth of micrococci }\end{array}$} \\
\hline & & \multicolumn{2}{|c|}{$\begin{array}{l}\text { oxidising glucose } \\
\text { (subgroups } 1-6 \dagger \text { ) was }\end{array}$} & \multicolumn{2}{|c|}{$\begin{array}{l}\text { not oxidising glucose } \\
\text { (subgroup } 7 \dagger \text { ) was }\end{array}$} \\
\hline & & present & absent & present & absent \\
\hline 6736 & Linoleate & 42 & 4 & 0 & 52 \\
\hline 6736 & Paromomycin & 42 & 4 & 0 & 52 \\
\hline 6732 & Paromomycin & 42 & 4 & 0 & 52 \\
\hline 6738 & Paromomycin & 42 & 4 & 0 & 52 \\
\hline
\end{tabular}

* Only variants that were stimulated to normal growth by fructose, acetate, pyruvate, oxaloacetate and aspartate showed satellitism.

$\dagger$ Baird-Parker (1965).

TABLE V

Comparison of minimum inhibitory concentration of aminoglucoside antibiotics for 3 sensitive strains of Staph. aureus, and for a dwarf-colony variant (strain 6736), under anaerobic and aerobic conditions

\begin{tabular}{|c|c|c|c|c|c|c|c|c|}
\hline \multirow{2}{*}{\multicolumn{2}{|c|}{ Strain }} & & \multicolumn{6}{|c|}{ Minimum inhibitory concentrations $(\mu \mathrm{g}$ per $\mathrm{ml})$ of } \\
\hline & & & neomycin & $\begin{array}{l}\text { strepto- } \\
\text { mycin }\end{array}$ & framycetin & $\begin{array}{l}\text { paromo- } \\
\text { mycin }\end{array}$ & kanamycin & $\begin{array}{l}\text { genta- } \\
\text { micin }\end{array}$ \\
\hline $\begin{array}{l}\text { Sensitive strair } \\
\text { aerobic } \\
\text { anaerobic }\end{array}$ & & $\dot{.}$ & $\begin{array}{r}0 \cdot 2 \\
6\end{array}$ & $\begin{array}{l}1 \cdot 5 \\
100\end{array}$ & $\begin{array}{r}0.5 \\
2\end{array}$ & $\begin{array}{r}0 \cdot 2 \\
6\end{array}$ & $\begin{array}{l}0 \cdot 5 \\
128\end{array}$ & $\begin{array}{r}0 \cdot 1 \\
3\end{array}$ \\
\hline $\begin{array}{l}\text { Sensitive strair } \\
\text { aerobic } \\
\text { anaerobic }\end{array}$ & $\begin{array}{l}2 \\
.\end{array}$ & . & $\begin{array}{l}0.2 \\
0.8\end{array}$ & $\begin{array}{r}0 \cdot 8 \\
6\end{array}$ & $\begin{array}{r}0.5 \\
4\end{array}$ & $\begin{array}{r}0.2 \\
6\end{array}$ & $\begin{array}{r}0.5 \\
16\end{array}$ & $\begin{array}{r}0 \cdot 1 \\
3\end{array}$ \\
\hline $\begin{array}{l}\text { Sensitive strair } \\
\text { aerobic } \\
\text { anaerobic }\end{array}$ & $\begin{array}{l}3 \\
\text {. }\end{array}$ & . & $\begin{array}{r}0 \cdot 2 \\
6\end{array}$ & $\begin{array}{r}0 \cdot 8 \\
6\end{array}$ & $\begin{array}{l}1 \\
8\end{array}$ & $\begin{array}{r}0 \cdot 2 \\
25\end{array}$ & $\begin{array}{r}0.5 \\
32\end{array}$ & $\begin{array}{r}0 \cdot 1 \\
3\end{array}$ \\
\hline $\begin{array}{c}\text { Dwarf-colony } \\
\text { aerobic } \\
\text { anaerobic }\end{array}$ & va & t. & $\begin{array}{r}6 \\
12\end{array}$ & $\begin{array}{l}50 \\
50\end{array}$ & $\begin{array}{l}8 \\
8\end{array}$ & $\begin{array}{l}25 \\
50\end{array}$ & $\begin{array}{l}32 \\
32\end{array}$ & $\begin{array}{l}3 \\
6\end{array}$ \\
\hline
\end{tabular}

and heated extracts of strains known to stimulate growth had no effect. As the stimulatory agent was strain-specific yet labile, the possibility that it might 
be a nucleic acid was tested. Incorporation of ribonucleases or deoxyribonucleases (Sigma Chemical Co. Ltd) into the medium and varying the calcium and magnesium concentration had no effect on the satellitism.

Further evidence of an oxidative defect in the variants was seen when sensitivity to aminoglucoside antibiotics was determined under anaerobic conditions. The MIC for the dwarf-colony variant of strain no. 6736 and for 3 aminoglucoside-sensitive wild strains of Staph. aureus under aerobic and

TABLE VI

Effect of the incorporation of 0.6 per cent. pyruvate $(w / v)$ in the medium on the minimum inhibitory concentration of aminoglucoside antibiotics for strain no. 6736 and its smallcolony variant

\begin{tabular}{|c|c|c|c|c|c|c|}
\hline \multirow{2}{*}{$\underset{\text { (medium) }}{\text { Strain }}$} & \multicolumn{6}{|c|}{ Minimum inhibitory concentrations ( $\mu \mathrm{g}$ per $\mathrm{ml}$ ) of } \\
\hline & neomycin & $\begin{array}{l}\text { strepto- } \\
\text { mycin }\end{array}$ & framycetin & $\begin{array}{c}\text { paromo- } \\
\text { mycin }\end{array}$ & kanamycin & $\begin{array}{l}\text { genta- } \\
\text { micin }\end{array}$ \\
\hline $\begin{array}{l}\text { Strain } 6736 \\
\quad \text { (nutrient agar) }\end{array}$ & $0 \cdot 2$ & $1 \cdot 5$ & 0.5 & $0 \cdot 2$ & 0.5 & $0 \cdot 1$ \\
\hline $\begin{array}{l}\text { Variant } 6736 \\
\quad \text { (nutrient agar) }\end{array}$ & 6 & 50 & 8 & 25 & 32 & 6 \\
\hline $\begin{array}{c}\text { Strain } 6736 \\
\quad \text { (nutrient } \\
\quad \text { per cent. pyrurate) }\end{array}$ & $0 \cdot 4$ & 3 & 1 & 0.4 & 0.5 & $0 \cdot 2$ \\
\hline $\begin{array}{c}\text { Variant } 6736 \\
\text { (nutrient agar }+0 . \dot{6} \\
\text { per cent. pyruvate) }\end{array}$ & $0 \cdot 8$ & 3 & 2 & $0 \cdot 8$ & 1 & $0 \cdot 4$ \\
\hline
\end{tabular}

anaerobic conditions are shown in table V. The wild strain of no. 6736 could not be included in the test because it grew poorly under anaerobic conditions. Anaerobic growth led to little change in the antibiotic resistance of the dwarfcolony variants, but the 3 sensitive " normal" staphylococci were more resistant to all the aminoglucosides under these conditions. Kogut, Lightbown and Isaacson (1965) have shown that oxidative metabolism is necessary for normal uptake of dihydrostreptomycin by bacteria. If oxidative metabolism could be promoted in the variants, they might be expected to become more sensitive to the antibiotics. This in fact happened; when 0.6 per cent. (w/v) pyruvate was incorporated into the medium the MIC for the variant was reduced, but that for the wild strain was little altered (table VI). The aminoglucoside resistance in these variants can therefore be accounted for by their defective oxidative metabolism failing to effect adequate uptake of the antibiotic.

\section{Survival of dwarf-colony variants on the skin}

The ability of the variants to survive on normal skin was investigated by a method described previously (Lacey, 1968a). The variants and wild strains 
were grown overnight in broth containing 0.6 per cent. (w/v) fructose and, after dilution, applied respectively to the right and left arm of human volunteers. A "Presson" label was applied to the skin over each inoculum, the arms were sampled after $5 \mathrm{hr}$ and the ratios of the sum of the square roots of the counts obtained from the two arms was calculated (table VII), after an adjustment had

TABLE VII

Survival of wild strains and of corresponding dwarf-colony variants on human skin under "Presson" labels for a period of $5 \mathrm{hr}$

\begin{tabular}{l|c|c}
\hline $\begin{array}{c}\text { Initial of } \\
\text { subject }\end{array}$ & $\begin{array}{c}\text { Serial number of wild strain } \\
\text { (source of variant in } \\
\text { parenthesis) }\end{array}$ & $\begin{array}{c}\text { Ratio* of sum of square roots of } \\
\text { counts of organisms recovered } \dagger \\
\text { (variant :wild strain) }\end{array}$ \\
\hline B. W. & 6736 (linoleate) & $1 \cdot 57: 1$ \\
A. R. & 6736 (linoleate) & $2 \cdot 05: 1$ \\
J. L. & 6736 (paromomycin) & $1 \cdot 24: 1$ \\
M.S. & 6736 (paromomycin) & $1 \cdot 16: 1$ \\
R. L. & 6732 (paromomycin) & $1 \cdot 43: 1$ \\
R. H. & 6732 (paromomycin) & $2 \cdot 02: 1$ \\
A. E. & 6738 (paromomycin) & $1 \cdot 80: 1$ \\
A. C. & 6738 (paromomycin) & $2 \cdot 18: 1$ \\
\hline
\end{tabular}

* Mean ratio $=1 \cdot 68: 1 ; t=4.82 ; P<0.001$.

$\dagger$ After correction for differences in the size of inoculum of the pair of organisms.

been made for differences in the size of the inoculum of the two organisms (Lacey, to be published). The variants survived significantly better $(\mathrm{P}<0.001)$ than the wild strains, probably because of their resistance to destruction by cutaneous lipid (Burtenshaw, 1942; Ricketts, Squire and Topley, 1951).

\section{Discussion}

Although Staphylococcus aureus has on occasion been found in pathological material entirely in the small-colony form (Hale, 1951; Sherris, 1952; Goudie and Goudie, 1955; Thomas and Cowlard, 1955; and Sompolinsky, ErnstGeller and Segal, 1967), these variants have often been obtained, either from such material or from laboratory cultures, by growth in the presence of various inhibitory agents. Among these are antibiotics, including streptomycin (Barbour, 1950; Browning and Adamson, 1950; Wise and Spink, 1954), lithium chloride (Hoffstadt and Youmans, 1932), barium salts (Youmans and Delves, 1942) and gentian violet (Hale, 1947). They were at one time thought to be a stage in the life cycle of the organisms-hence the terms " $G$ " or "gonidial" forms. Some dwarf-colony forms appeared to have a defect in a specific metabolic pathway. Thus, the strains isolated by Sompolinsky et al. from lesions of bovine mastitis had defects in thiamine synthesis, and other strains from human sources grew normally if the atmosphere was enriched with $\mathrm{CO}_{2}$.

The small-colony forms described here were isolated after exposure of Staph. aureus to two different agents, but possessed similar properties. It is 
unlikely that a long-chain fatty acid and an aminoglucoside antibiotic, being structurally dissimilar, would induce the same change in an organism. Mutation to streptomycin resistance is known to occur before exposure to the drug (Lederberg and Lederberg, 1952), and it is likely that these variants had arisen in the cultures as mutants. Their frequency of between 1 in $10^{-6}$ and 1 in $10^{-9}$ is of the same order as that of other bacterial mutations. Since the variants were obtained from all 10 of the strains exposed to paromomycin, this mutation would seem a general property of Staph. aureus. The genetic basis of the defect in these variants is uncertain. Since partial revertants have been identified in which growth is normal in rate but not in colour, it is unlikely that a single chromosomal deletion would account for all the features. The ready reversion to colonies indistinguishable from the wild strain suggests inactivation rather than destruction of a segment of the chromosome. Chabbert (1967) considered that the determinant for gentamicin resistance in micro-organisms is always chromosomal.

There are other instances of changes in the pigmentation of catalasepositive cocci associated with the acquisition of antibiotic resistance. The strains described by Barber (1955) had some features similar to the variants described here; she isolated golden-coloured mutants of the white colonies of the Oxford staphylococcus after exposing them to chloroform or to streptomycin. They were resistant to streptomycin and were unstable, although they showed little change in colony size. Similarly, Mayr-Harting (1955) found that artificially selected penicillin-resistant variants of the Oxford staphylococcus exhibited increased pigmentation. Willis, Smith and O'Connor (1966) found that certain strains of Staph. aureus that were resistant to several antibiotics produced a characteristic lemon-yellow pigment.

On the other hand, spontaneous changes in pigmentation in the Micrococcaceae usually involve a loss of the character (Cowan, 1962). However, Lacey and Boswell (1968) found that most yellow-pigmented micrococci (Micrococcus subgroup 7) were relatively resistant to paromomycin, but that most of the white micrococci were fully sensitive to this antibiotic.

Streptomycin-resistant strains of Staph. aureus became common in hospitals soon after the antibiotic was introduced. Although neomycin was used for several years before resistant strains emerged, by 1960 they had become a problem in some hospitals (Finegold and Gaylor, 1960; Quie, Collin and Cardle, 1960) and have since become widespread in distribution (Jevons, John and Parker, 1966). Sudden proliferation of neomycin-resistant staphylococci has followed the topical application of the drug (Lowbury et al., 1964; Rountree and Beard, 1965; Alder and Gillespie, 1967). Whether the dwarfcolony variants described here have any relevance to clinical problems is not clear, but their resistance to aminoglucoside antibiotics might constitute a temporary mechanism for the survival of a strain in the presence of these antibiotics, with reversion to normal forms after the antibiotic has been withdrawn. Neomycin and its analogues form complexes in vitro with long-chain fatty acids including linoleic acid (Lacey, 1968b). This fatty acid occurs widely in human tissues, and such complexes might be potent selectors of these dwarf 
forms in vivo, on account of both their fatty acid and their aminoglucoside content. The persistence of the organism in the presence of antibiotic might also in some way relate to the emergence of strains resistant to aminoglucoside antibiotics. Further investigation is needed to test these hypotheses.

\section{SUMMARY}

The exposure of cultures of Staphylococcus aureus to linoleic acid selected variants that were resistant to aminoglucoside antibiotics. Variants with identical characters were isolated by exposure to an aminoglucoside antibiotic, paromomycin.

The variants grew on nutrient agar as small, intensely pigmented colonies, but tended to revert to the original colonial form. The revertants were sensitive to aminoglucoside antibiotics.

Some of the variants were stimulated to normal growth only by fructose, and others by fructose, acetate, pyruvate, oxaloacetate and aspartate. The latter variants exhibited satellitism around colonies of certain Gram-positive cocci.

Dwarf-colony variants persisted better than the parent staphylococci on normal skin. Their occurrence in vivo might be relevant to the survival of staphylococci on carriage sites, particularly in patients being treated with aminoglucoside antibiotics.

I am grateful to Dr V. G. Alder and Professor W. A. Gillespie for valuable criticism and the Governors of the United Bristol Hospitals for a grant out of their Research Funds.

\section{REFERENCES}

Alder, V. G., AND Gillespie, W. A. . 1967. Lancet, 2, 1062.

Batrd-Parker, A. C. . . . . 1965. J. Gen. Microbiol., 38, 363.

BARBer, MARY . . . . . . 1955. Ibid., 13, 338.

Barber, Mary, and Waterworth, 1966. Br. Med.J., 1, 203.

PAMELA M.

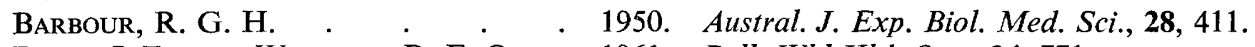

Blair, J. E., AND Williams, R. E. O. . 1961. Bull. Wld Hlth Org., 24, 771.

Browning, C. H., and Adamson, H. S. 1950. J. Path. Bact., 62, 499.

Burtenshaw, J. M. L. . . . . 1942. J. Hyg., Camb., 42, 184.

Chabbert, Y. A. . . . . 1967. I Int. Symp. Gentamicin, Paris (publ. at Lucerne), p. 19.

Cowan, S. T. - . . . . - 1962. J. Appl. Bact., 25, 324.

Finegold, S. M., AND GaYlor, D. W. . 1960. New Engl. J. Med., 263, 1110.

Gonzalez, C., ANd Sierra, G. 1961. Nature, Lond., 189, 601.

Goudie, J. G., AND GoudIE, R. B. 1955. J. Clin. Path., 8, 284.

HAle, J. H. . . . . . . . 1947. Br. J. Exp. Path., 28, 202.

" . . . . . . . 1951. Ibid., 32, 307.

Hoffstadt, Rachel E., and Youmans, 1932. J. Infect. Dis., 51, 216. G. P.

Jevons, M. Patricia, John, Madeleine, 1966. J. Clin. Path., 19, 305. AND PARKER, M. T.

Kogut, Margot, Lightbown, J. W., 1965. J. Gen. Microbiol., 39, 155. AND ISAACSON, $\mathbf{P}$. 


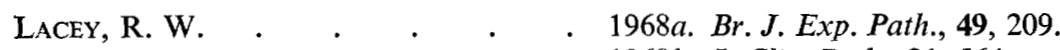

. · · · 1968b. J. Clin. Path., 21, 564.

LEDERBERG, J., AND LeDERBERG, EsTher 1952. J. Bact., 63, 399.

M.

Lowbury, E. J. L., BabB, J. R., Brown, 1964. J. Hyg., Camb., 62, 221. VIVIEN I., AND COLlins, B. J.

Mayr-Harting, ANNA . . . 1955. J. Gen. Microbiol., 13, 9.

Miles, A. A., Misra, S. S., AND Irwin, 1938. J. Hyg., Camb., 38, 732. J. O.

Quie, P. G., Collin, MaY, AND Cardle, 1960. Lancet, 2, 124. J. B.

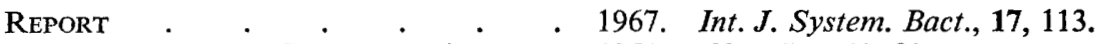

Ricketts, C. R., SQuire, J. R., AND 1951. Clin. Sci., 10, 89. TOPLEY, ELIZABETH

Rountree, Phyllis M., and Beard, 1965. Med.J. Austral., 1, 498. MARY A.

Sherris, J. C. . $\quad$. $\quad$. $\quad$. 1952. J. Clin. Path., 5, 354.

Sompolinsky, D., ERnSt-Geller, 1967. J. Gen. Microbiol., 48, 205. ZIPPORA, AND SEGAL, S.

Thomas, Mair E. M. . - . 1955. J. Clin. Path., 8, 288.

Willis, A. T., SMITH, J. A., AND 1966. J. Path. Bact., 92, 345. O'CONNOR, J. JEAN

Willis, A. T., AND Turner, G. C. $\quad$. 1962. Ibid., 84, 337.

WiSE, R. J., AND SPINK, W. W. - $\quad$ - 1954. J. Clin. Invest., 33, 1611.

Youmans, G. P., And Delves, Edna 1942. J. Bact., 44, 127. 